\title{
Factors That Influence Measurements and Accurate Evaluation of Stent Apposition by Optical Coherence Tomography Assessment Using a Phantom Model
}

\author{
Takahiro Sawada, MD; Junya Shite, MD; Noriyuki Negi, RT*; Toshiro Shinke, MD; \\ Yusuke Tanino, MD; Daisuke Ogasawara, MD; Hiroyuki Kawamori, MD; Hiroki Kato, MD; \\ Naoki Miyoshi, MD; Naoki Yoshino, MD; Amane Kozuki, MD; \\ Masanobu Koto, RT*; Ken-ichi Hirata, MD
}

\begin{abstract}
Background: Factors influencing measurements and accurate evaluation of stent apposition by optical coherence tomography (OCT) are not established.

Methods and Results: Phantom models of known luminal sizes and lengths were evaluated by OCT under various conditions and measurements were compared with actual values. Stents implanted into phantom models were examined by OCT to validate the measurement point on the stent strut surface for accurate evaluation of stent apposition. Strut thickness was measured at 3 points (midpoint, inner and outer surfaces of the stent shadow). The precision of OCT measurements of lumen diameter and area was satisfactory when the image wire was positioned in the center, but the error and deviation were unsatisfactory when the image wire was positioned eccentrically using a low frame acquisition rate. Longitudinal OCT measurements were close to actual values under all conditions examined. Measurements from the midpoint of the stent shadow to the adjacent vessel wall surface coincided with actual stent thickness.

Conclusions: Significant measurement error can occur if the image wire is positioned eccentrically with a lower frame acquisition rate than specified by the manufacturer. To accurately evaluate stent apposition, the stent surface should be measured from the center of the stent reflection. (Circ J 2009; 73: 1841-1847)
\end{abstract}

Key Words: Imaging; Percutaneous coronary intervention (PCI); Optical coherence tomography (OCT)

I ntravascular ultrasound (IVUS) is now routinely used for percutaneous coronary intervention (PCI) procedures, because it provides valuable information about the arterial structure, such as the vessel size and stent condition after implantation. ${ }^{1-4}$ The low resolution (100$200 \mu \mathrm{m})$ of IVUS, however, limits the ability to study fine architectural vascular changes induced by PCI. Optical coherence tomography (OCT) is a relatively new imaging modality that generates images with micron-scale resolution. ${ }^{5}$ OCT provides intra-coronary images $(10-20 \mu \mathrm{m})$ with an approximately 10-fold greater resolution than IVUS. ${ }^{6}$ Histopathologic studies revealed that OCT provides an accurate representation of the intima media thickness ${ }^{7}$ and fibrous cap thickness. ${ }^{8}$ Neointimal coverage of silorimuseluting stents and stent position (apposition or mal-apposition) can be precisely evaluated using OCT. ${ }^{9-12}$ Thus, OCT is expected to be a useful imaging modality for a better understanding of the pathophysiology of atherosclerosis, assessment of coronary stent position, and for PCI.

There are a few limitations, however, to the use of OCT in vivo. Due to limited penetration $(2 \mathrm{~mm})$, OCT cannot be used to evaluate large vessels and positively remodeled vessels. ${ }^{13}$ The location of the image wire, vessel size, as well as heart motion artifacts might affect the accuracy of OCT measurements and image quality. Furthermore, the best method for measuring stent strut thickness with OCT has not yet been established because the infra-red light does not transmit through metal and the outer surface of the stent strut cannot be observed as a result of light reflection. Thus, the OCT methods of measuring stent apposition and neointimal thickness have not been determined. In the present study, we evaluated the factors that influence the accuracy of OCT measurements using in vitro phantom models under various conditions to validate the OCT artifact effect. In addition, we determined the optimum point for measuring the stent strut surface for accurately evaluating stent apposition using phantom models.

\section{Methods}

In the present study, we used an OCT image wire (ImageWire ${ }^{\mathrm{TM}}$, LightLab Imaging, Westford, MA, USA) and IVUS catheter (Revolution ${ }^{\mathrm{TM}}$, Volcano Therapeutics, Inc, Rancho Cordova, CA, USA). Because we usually use

(Received February 13, 2009; revised manuscript received May 19, 2009; accepted May 20, 2009; released online July 31, 2009)

Division of Cardiovascular Medicine, Department of Internal Medicine, Kobe University Graduate School of Medicine, *Department of Radiological Technology, Kobe University Hospital, Kobe, Japan

Mailing address: Junya Shite, MD, Division of Cardiovascular Medicine, Department of Internal Medicine, Kobe University Graduate School of Medicine, 7-5-1 Kusunoki-cho, Chuo-ku, Kobe 650-0017, Japan. E-mail: shite@med.kobe-u.ac.jp

All rights are reserved to the Japanese Circulation Society. For permissions, please e-mail: cj@j-circ.or.jp 

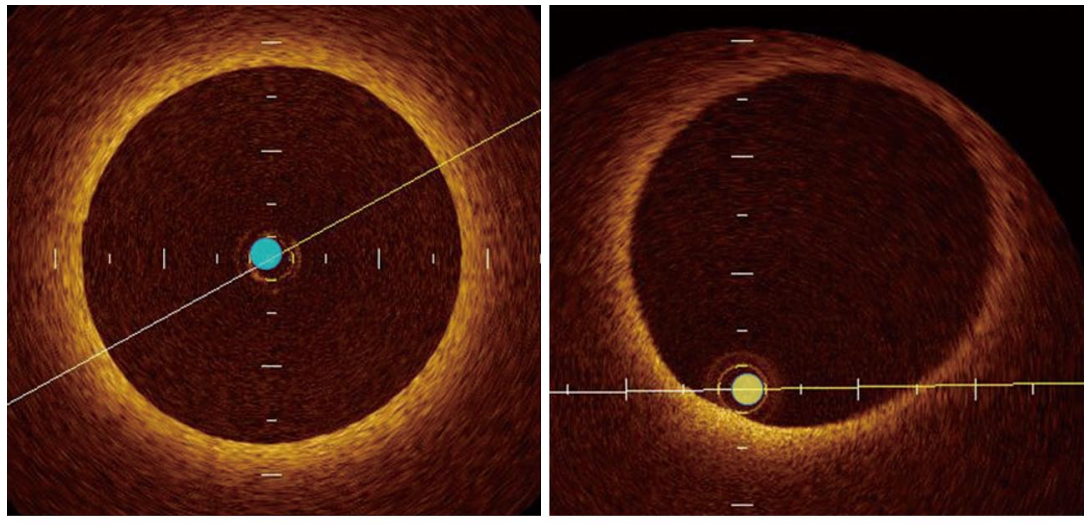

Image wire in center

Image wire off center

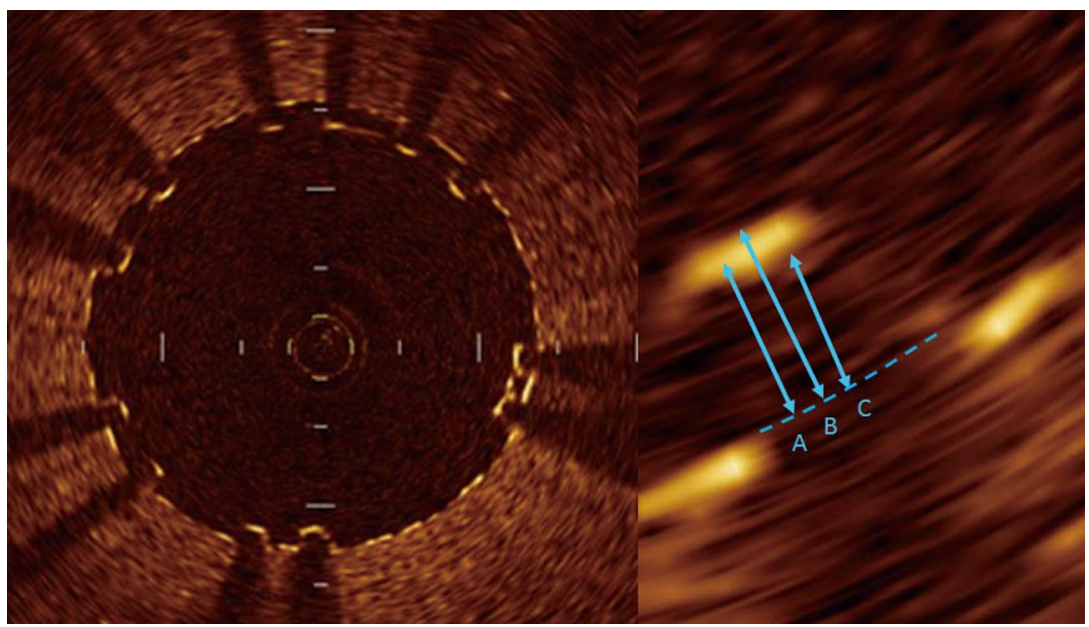

Figure 1. (A) An in-center image. The optical coherence tomography (OCT) image wire is positioned at the center of the model $(>0.5 \mathrm{~mm}$ from the model wall). (B) An off-center image. The OCT image wire is positioned eccentrically toward the side of the model wall $(<0.5 \mathrm{~mm}$ from the model wall).

Figure 2. The point of measurement on the stent strut surface by optical coherence tomography $(\mathrm{OCT})$. Dis. A is the distance between the midpoint of the stent strut reflection and the adjacent model wall surface. Dis. B is the distance between the inner surface stent strut reflection and the adjacent model wall surface. Dis. $C$ is the distance between the outer surface stent strut reflection and the adjacent model wall surface.
Lactated Ringer's solution to clear blood from coronary vessels while performing OCT in vivo, all OCT and IVUS images were obtained in a tank filled with $37^{\circ} \mathrm{C}$ Lactated Ringer's solution. All OCT measurements were done after manual calibration based on the reflection of the OCT image wire.

First, we evaluated the detection limit of the OCT field of view and the factors that influence the OCT measurements. Circular, styrene plastic arterial models (Evergreen Scale Models, Inc, Woodinville, WA, USA) with luminal diameters of $\varnothing 1.8-\mathrm{mm}, \varnothing 3.3-\mathrm{mm}, \varnothing 4.9-\mathrm{mm}$, and $\varnothing 6.0-\mathrm{mm}$ were observed by OCT. The arterial model was manually positioned in a tank filled with Lactated Ringer's solution and the image wire was advanced into the model up to the distal end and fixed in place with cellophane tape. Motorized pullback was performed at 2 different speeds, 1.0 or $2.0 \mathrm{~mm} / \mathrm{s}$, 3 times. OCT images were also acquired at 2 frame acquisition rates $(8.2 \mathrm{~F} / \mathrm{s}$ or $15.6 \mathrm{~F} / \mathrm{s})$. [The commercially available OCT system (LightLab Imaging) is configured at $15.6 \mathrm{~F} / \mathrm{s}$ of frame acquisition rate]. The OCT images were digitally archived on a personal computer for off-line analysis and every $10^{\text {th }}$ OCT frame was selected for evaluation. Diameters (maximum and minimum) and area were measured in all images. The ratios of the maximum and minimum model diameters were calculated to evaluate image distortion. These measurements were obtained with the OCT image wire positioned either at the center of each model (in-center,
$>0.5 \mathrm{~mm}$ from the phantom wall) and or closer to the wall of the model (off-center, $<0.5 \mathrm{~mm}$ from the phantom wall; Figure 1). The plastic model diameter and area were also examined by IVUS $(30 \mathrm{~F} / \mathrm{s}$ frame-rate and $0.5 \mathrm{~mm} / \mathrm{s}$ pullback-speed) for every $0.5-\mathrm{mm}$ cross-section. The off-line analysis of both the OCT and IVUS data was performed using a quantitative coronary ultrasound cardiovascular measurement system (CMS-Medis Medical Imaging Systems). OCT and IVUS measurements were compared with the actual model diameter and area, and with each other. We excluded poor images from which we could not measure the diameter and area.

For longitudinal measurements, a known length $(30.0 \mathrm{~mm})$ of both a straight and a $90^{\circ}$ angulated rubber arterial model (Shinoda Gomu Co, Ltd, Tokyo, Japan) was examined in the same manner using 2 different frame acquisition rates $(8.2 \mathrm{~F} / \mathrm{s}, 15.6 \mathrm{~F} / \mathrm{s})$ and pullback speeds $(1.0 \mathrm{~mm} / \mathrm{s}$, $2.0 \mathrm{~mm} / \mathrm{s}$ ). Each longitudinal measurement was taken at 10 different times. Measurements were then compared with the actual value.

We then evaluated the reproducibility of the crosssectional shape of the OCT image. The $\varnothing 1.8-\mathrm{mm}$ circular model and the quadrangular phantom model of the same size were evaluated under the same conditions (frame-rate, $8.2 \mathrm{~F} / \mathrm{s}$ and $15.6 \mathrm{~F} / \mathrm{s}$, and positioned either in-center or offcenter). The evaluated items were the shape difference of phantom model form and the difference of intensity that 
Table 1. Comparison Between IVUS Measurements and OCT Measurements of Cross-Sectional Measurements

\begin{tabular}{|c|c|c|c|c|c|}
\hline & \multirow{2}{*}{ IVUS $(30 \mathrm{~F} / \mathrm{s}, 0.5 \mathrm{~mm} / \mathrm{s})$} & \multicolumn{2}{|c|}{ OCT $(15.6 \mathrm{~F} / \mathrm{s})$} & \multicolumn{2}{|c|}{ OCT $(8.2 \mathrm{~F} / \mathrm{s})$} \\
\hline & & In-center & Off-center & In-center & Off-center \\
\hline \multicolumn{6}{|l|}{ Pullback speed: $1.0 \mathrm{~mm} / \mathrm{s}$} \\
\hline \multicolumn{6}{|l|}{ Phantom diameter (mm) } \\
\hline$\varnothing 1.8-\mathrm{mm}$ & $1.76 \pm 0.05(\mathrm{~mm})$ & $1.82 \pm 0.04(\mathrm{~mm})$ & $1.82 \pm 0.06(\mathrm{~mm})$ & $1.79 \pm 0.10(\mathrm{~mm})$ & $1.95 \pm 0.15^{+}(\mathrm{mm})$ \\
\hline$\varnothing 3.3-\mathrm{mm}$ & $3.37 \pm 0.05(\mathrm{~mm})$ & $3.26 \pm 0.05(\mathrm{~mm})$ & $3.26 \pm 0.10(\mathrm{~mm})$ & $3.38 \pm 0.10(\mathrm{~mm})$ & $3.58 \pm 0.14+(\mathrm{mm})$ \\
\hline$\varnothing 4.9-\mathrm{mm}$ & $4.94 \pm 0.14(\mathrm{~mm})$ & $4.83 \pm 0.10(\mathrm{~mm})$ & NA & $4.98 \pm 0.08(\mathrm{~mm})$ & NA \\
\hline Ratio of major and minor diameter & $1.01 \pm 0.01$ & $1.01 \pm 0.01$ & $1.04 \pm 0.03 *$ & $1.01 \pm 0.03$ & $1.06 \pm 0.03 *$ \\
\hline \multicolumn{6}{|l|}{ Phantom area $\left(\mathrm{mm}^{2}\right)$} \\
\hline $2.54-\mathrm{mm}^{2}$ & $2.45 \pm 0.06\left(\mathrm{~mm}^{2}\right)$ & $2.56 \pm 0.11\left(\mathrm{~mm}^{2}\right)$ & $2.55 \pm 0.10\left(\mathrm{~mm}^{2}\right)$ & $2.63 \pm 0.26\left(\mathrm{~mm}^{2}\right)$ & $3.53 \pm 0.41+\left(\mathrm{mm}^{2}\right)$ \\
\hline $8.55-\mathrm{mm}^{2}$ & $8.68 \pm 0.05\left(\mathrm{~mm}^{2}\right)$ & $8.30 \pm 0.07\left(\mathrm{~mm}^{2}\right)$ & $8.37 \pm 0.14\left(\mathrm{~mm}^{2}\right)$ & $9.03 \pm 0.55\left(\mathrm{~mm}^{2}\right)$ & $11.8 \pm 0.47+\left(\mathrm{mm}^{2}\right)$ \\
\hline $18.85-\mathrm{mm}^{2}$ & $18.78 \pm 0.08\left(\mathrm{~mm}^{2}\right)$ & $18.41 \pm 0.39\left(\mathrm{~mm}^{2}\right)$ & NA & $19.4 \pm 0.54\left(\mathrm{~mm}^{2}\right)$ & NA \\
\hline \multicolumn{6}{|l|}{ Pullback speed: $2.0 \mathrm{~mm} / \mathrm{s}$} \\
\hline \multicolumn{6}{|l|}{ Phantom diameter (mm) } \\
\hline$\emptyset 1.8-\mathrm{mm}$ & $1.76 \pm 0.05(\mathrm{~mm})$ & $1.81 \pm 0.04(\mathrm{~mm})$ & $1.79 \pm 0.06(\mathrm{~mm})$ & $1.85 \pm 0.11(\mathrm{~mm})$ & $2.08 \pm 0.16^{+}(\mathrm{mm})$ \\
\hline$\varnothing 3.3-\mathrm{mm}$ & $3.37 \pm 0.05(\mathrm{~mm})$ & $3.29 \pm 0.03(\mathrm{~mm})$ & $3.35 \pm 0.09(\mathrm{~mm})$ & $3.38 \pm 0.12(\mathrm{~mm})$ & $3.66 \pm 0.18^{+}(\mathrm{mm})$ \\
\hline$\varnothing 4.9-\mathrm{mm}$ & $4.94 \pm 0.14(\mathrm{~mm})$ & $4.83 \pm 0.06(\mathrm{~mm})$ & NA & $4.94 \pm 0.14(\mathrm{~mm})$ & NA \\
\hline Ratio of major and minor diameter & $1.01 \pm 0.01$ & $1.01 \pm 0.01$ & $1.05 \pm 0.03 *$ & $1.03 \pm 0.03$ & $1.06 \pm 0.06^{*}$ \\
\hline \multicolumn{6}{|l|}{ Phantom area $\left(\mathrm{mm}^{2}\right)$} \\
\hline $2.54-\mathrm{mm}^{2}$ & $2.45 \pm 0.06\left(\mathrm{~mm}^{2}\right)$ & $2.52 \pm 0.10\left(\mathrm{~mm}^{2}\right)$ & $2.48 \pm 0.09\left(\mathrm{~mm}^{2}\right)$ & $2.81 \pm 0.29\left(\mathrm{~mm}^{2}\right)$ & $3.53 \pm 0.40^{+}\left(\mathrm{mm}^{2}\right)$ \\
\hline $8.55-\mathrm{mm}^{2}$ & $8.68 \pm 0.05\left(\mathrm{~mm}^{2}\right)$ & $8.46 \pm 0.05\left(\mathrm{~mm}^{2}\right)$ & $8.52 \pm 0.15\left(\mathrm{~mm}^{2}\right)$ & $9.56 \pm 0.73\left(\mathrm{~mm}^{2}\right)$ & $11.75 \pm 0.87+\left(\mathrm{mm}^{2}\right)$ \\
\hline $18.85-\mathrm{mm}^{2}$ & $18.78 \pm 0.08\left(\mathrm{~mm}^{2}\right)$ & $18.36 \pm 0.33\left(\mathrm{~mm}^{2}\right)$ & NA & $19.3 \pm 0.85\left(\mathrm{~mm}^{2}\right)$ & NA \\
\hline
\end{tabular}

$* \mathrm{P}<0.0001$ vs IVUS, $\mathrm{P}<0.0001$ vs OCT in-center, ${ }^{+} \mathrm{P}<0.001$ vs IVUS.

IVUS, intravascular ultrasound; OCT, optical coherence tomography.

might result from a difference in the image wire distance. We calculated the shape reproducibility rate (number of frames that appeared to have a shape close to that of the actual phantom/total number of frames) to confirm shape reproducibility. We also counted the number of images with image wire motion artifacts and calculated the motion artifact rate (number of frames with motion artifact/total number of frames).

Last, we determined the accuracy of the measurement point of the stent strut surface by OCT. We used the following stents: 2 drug-eluting stents (DES); Cypher ${ }^{\mathrm{TM}}$ (Cordis, Johnson and Johnson Company) and Taxus Express ${ }^{\mathrm{TM}}$ (Boston Scientific Corporation); and 7 bare metal stent (BMS); VelocityTM (Cordis, Johnson and Johnson Company), Express2 $^{\mathrm{TM}}$ (Boston Scientific Corporation), Duraflex ${ }^{\mathrm{TM}}$ (Avantec Vascular Corp), Driver ${ }^{\mathrm{TM}}$ (Medtronic) and TSUNAMITM (Terumo). We implanted each $\varnothing 3.0-\mathrm{mm}$ stent into a rubber arterial phantom model with a $\varnothing 3.0-\mathrm{mm}$ luminal diameter (Shinoda Gomu Co, Ltd) at a maximum durable pressure. In each model, OCT pullback was performed 3 times with a pullback-speed of a $1.0 \mathrm{~mm} / \mathrm{s}$ and a frame-rate of $15.6 \mathrm{~F} / \mathrm{s}$. We then selected every $10^{\text {th }} \mathrm{OCT}$ frame in which the OCT image wire was positioned incenter. We measured the distance between the midpoint of the stent strut reflection and the adjacent vessel wall surface (Dis. A), the distance between the inner surface of the stent strut reflection and the adjacent vessel wall surface (Dis. B), and the distance between the outer surface of the stent strut reflection and the adjacent vessel wall surface (Dis.C; Figure 2). We determined the midpoint as follows; we first measured the width of stent strut reflection and divided the value in half. The point of the half distance from the inner surface of the stent strut reflection was defined as the midpoint. We compared these measurements to the manufacturer's specified strut thickness.

Especially in the case of Velocity ${ }^{\mathrm{TM}}$ stents, we compared the difference in stent strut thickness measurements evaluated using the method of Dis. A in relation to the image wire position. Further, we measured the distance from the image wire to the stent strut, and evaluated the impact of the strut thickness measurements (Dis. A) in relation to the distance from the image wire.

All measurements were read by 2 independent observers. The first observer repeated a blind analysis of all the data at 2 separate time points (with at least a 1-month interval between the 2 analyses).

\section{Statistical Analysis}

Continuous variables are shown as mean \pm standard deviation. The Bland-Altman plot was used to assess the differences between the OCT measurements of the lumen diameter and area with the actual values, and between stent strut thickness as measured by OCT and the manufacturerspecified nominal strut thickness. We also used the BlandAltman plot to estimate inter-observer and intra-observer variability. The relationship between OCT measurements and IVUS measurements was investigated using a Pearson's correlation coefficient. Statview version 5.0 (SAS, Cary, NC, USA) and Medcalc (Medcalc, version 9.3; Medcalc Software, Mariakerke, Belgium) were used for data analysis. A 2-tailed P-value of less than 0.05 was considered statistically significant.

\section{Results}

\section{The Accuracy of OCT Measurements and the Limitation of OCT Field of View}

The OCT and IVUS measurements of the lumen diameter of each size of the phantom model are shown in Table 1. We could not observe the entire $\varnothing 6.0$-mm model by OCT even if the image wire was positioned in-center. We could not obtain the whole image of the $\varnothing 4.9$-mm model, when the image wire was positioned off-center. Therefore, neither the lumen diameter nor the area of the $\varnothing 4.9-\mathrm{mm}$ model could be measured off-center. The average OCT measurements (diameter and area) of each model at a $15.6 \mathrm{~F} / \mathrm{s}$ frame-rate were approximately equal with the IVUS measurements (Pearson's correlation coefficients: $r>0.999$ ) and 
Table 2. Comparison Between IVUS Measurements and OCT Measurements of Longitudinal Measurements

\begin{tabular}{|c|c|c|c|c|c|}
\hline \multirow{2}{*}{ Phantom form } & \multirow{2}{*}{ IVUS $(30 \mathrm{~F} / \mathrm{s}, 0.5 \mathrm{~mm} / \mathrm{s})$} & \multicolumn{2}{|c|}{ OCT $15.6 \mathrm{~F} / \mathrm{s}$} & \multicolumn{2}{|c|}{ OCT $8.2 \mathrm{~F} / \mathrm{s}$} \\
\hline & & $1.0 \mathrm{~mm} / \mathrm{s}$ & $2.0 \mathrm{~mm} / \mathrm{s}$ & $1.0 \mathrm{~mm} / \mathrm{s}$ & $2.0 \mathrm{~mm} / \mathrm{s}$ \\
\hline Straight (30.0-mm) & $30.13 \pm 0.59(\mathrm{~mm})$ & $30.14 \pm 0.45(\mathrm{~mm})$ & $30.06 \pm 0.51(\mathrm{~mm})$ & $30.17 \pm 0.71(\mathrm{~mm})$ & $30.15 \pm 0.71(\mathrm{~mm})$ \\
\hline Angulated (30.0-mm) & $28.92 \pm 0.64(\mathrm{~mm})$ & $28.98 \pm 0.37(\mathrm{~mm})$ & $29.00 \pm 0.41(\mathrm{~mm})$ & $29.22 \pm 0.74(\mathrm{~mm})$ & $29.3 \pm 0.84(\mathrm{~mm})$ \\
\hline
\end{tabular}

Abbreviations see in Table 1.

Image wire (in-center)

$15.6 \mathrm{~F} / \mathrm{s}$
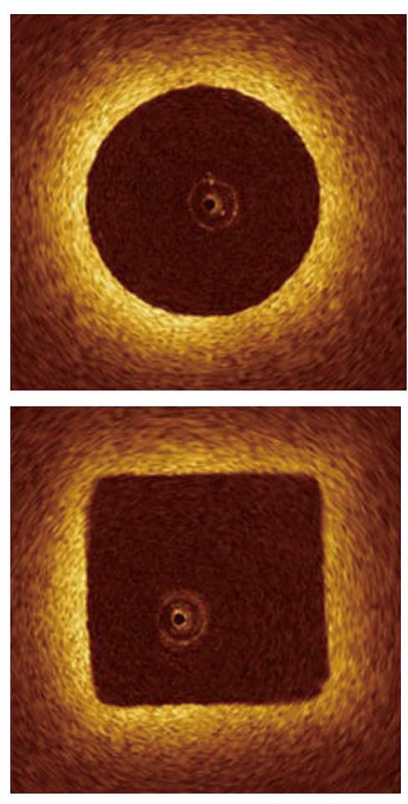

Distortion ( - )
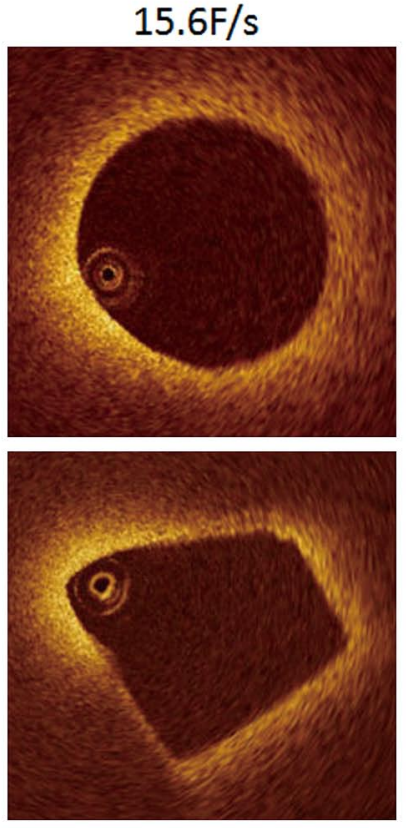

Change in brightness and distortion
$8.2 \mathrm{~F} / \mathrm{s}$
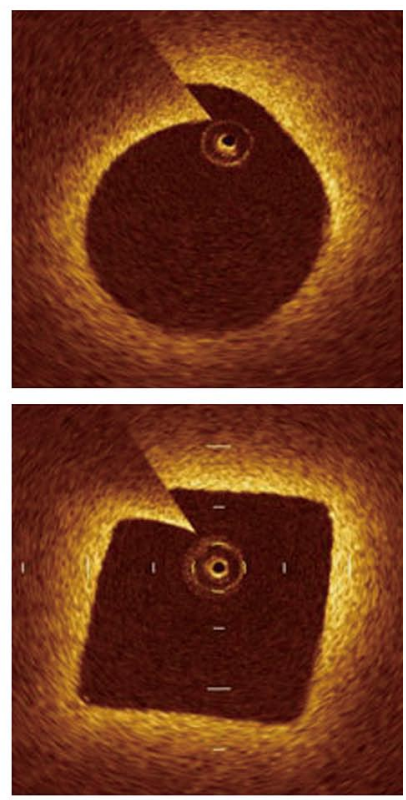

Motion artifact $(+)$

(Sew-up)

Figure 3. An in-center image is shown on the Left. Both the circular and quadrangular models are shown. An off-center image is shown in the Middle panel. The image produced is distorted so that is appears elliptical, especially when using a low frame-rate. The brightness of the far side phantom model surface from the image wire was low. An image of motion artifact (sew-up) is shown on the Right. Motion artifact occurs more frequently with a low frame-rate.

identical to the actual value whether the image wire was positioned in-center or off-center. The ratios of the maximum and minimum diameter in the off-center position, however, were significantly larger than those of the in-center position for all model size $(1.04 \pm 0.03$ vs $1.01 \pm 0.01, \mathrm{P}<0.0001)$. The pullback speed did not affect OCT cross-sectional measurements. At a $8.2 \mathrm{~F} / \mathrm{s}$ frame-rate, however, although the average measurements in-center were almost equal to the IVUS measurements (Pearson's correlation coefficients: $r>0.999)$ and actual lumen diameter, the standard deviations of OCT measurements $(8.2 \mathrm{~F} / \mathrm{s}$ in-center) were greater than those of the IVUS measurements and those $15.6 \mathrm{~F} / \mathrm{s}$ in all model sizes. Further, the error of OCT measurements $(8.2 \mathrm{~F} / \mathrm{s}$, off-center) was larger than that of $15.6 \mathrm{~F} / \mathrm{s}$ for all models. The ratios of the maximum and minimum diameters in the off-center position were also significantly larger than those of the in-center position for all model sizes $(1.06 \pm 0.03$ vs $1.01 \pm 0.03, \mathrm{P}<0.0001)$. The pullback speed did not affect OCT measurements, even at the $8.2 \mathrm{~F} / \mathrm{s}$ frame-rate.

The longitudinal measurements are shown in Table 2. The measurements of the straight models were almost identical to the actual values in all conditions examined. In the angulated model, the longitudinal OCT measurements tended to be shorter than the actual values in all conditions examined.

The estimated limit of agreement for the intra- and interobserver variability in the OCT measurements was reasonable, based on the Bland-Altman plot. [diameter measurements by OCT (mean difference, \%error): intra-observer, 11.2 $\pm 4.2 \mu \mathrm{m} ; 3.3 \%$, inter-observer; $17.5 \pm 5.0 \mu \mathrm{m}, 5.2 \%$; area measurements by OCT (mean difference, \%error): intra-observer, $0.10 \pm 0.09 \mathrm{~mm}^{2} ; 9.7 \%$, inter-observer; $0.14 \pm$ $\left.0.12 \mathrm{~mm}^{2}, 13.5 \%\right]$.

\section{The Visual Reproducibility of the Shape of Cross-Section}

When the image wire was positioned in-center and the frame-rate was $15.6 \mathrm{~F} / \mathrm{s}$, the shape reproducibility rate was good $(86.4 \%)$. When the image wire was positioned offcenter, the circular OCT cross-sectional images, however, were distorted and became elliptical, especially at the low frame-rate, and their shape reproducibility rate was $33.2 \%$ (Figure 3). When the image wire was positioned off-center, the brightness of the far side phantom surface from the 
Table 3. Comparison Between Dis. A and Manufacturer's Specification Stent Strut Thickness

\begin{tabular}{lcccc}
\hline Stent & $\begin{array}{c}\text { Manufacturer's specified } \\
\text { stent strut thickness }\end{array}$ & $\begin{array}{c}\text { Dis. A } \\
\text { (difference) }\end{array}$ & $\begin{array}{c}\text { Dis. B } \\
\text { (difference) }\end{array}$ & $\begin{array}{c}\text { Dis. C } \\
\text { (difference) }\end{array}$ \\
\hline Velocity & $140 \mu \mathrm{m}(0.0055 \mathrm{inch})$ & $1.7 \pm 13.3 \mu \mathrm{m}$ & $14.6 \pm 16.2 \mu \mathrm{m}$ & $25.1 \pm 16.8 \mu \mathrm{m}$ \\
Express & $132 \mu \mathrm{m}(0.0052 \mathrm{inch})$ & $4.7 \pm 11.0 \mu \mathrm{m}$ & $15.2 \pm 12.1 \mu \mathrm{m}$ & $24.7 \pm 13.2 \mu \mathrm{m}$ \\
Duraflex & $114 \mu \mathrm{m}(0.0045 \mathrm{inch})$ & $3.0 \pm 12.1 \mu \mathrm{m}$ & $16.6 \pm 12.2 \mu \mathrm{m}$ & $22.7 \pm 15.5 \mu \mathrm{m}$ \\
Driver & $91 \mu \mathrm{m}(0.0036 \mathrm{inch})$ & $0.5 \pm 8.5 \mu \mathrm{m}$ & $17.3 \pm 11.0 \mu \mathrm{m}$ & $16.3 \pm 10.3 \mu \mathrm{m}$ \\
TSUNAMI & $79 \mu \mathrm{m}(0.0031$ inch) & $0.04 \pm 11.4 \mu \mathrm{m}$ & $17.6 \pm 11.4 \mu \mathrm{m}$ & $17.6 \pm 15.4 \mu \mathrm{m}$ \\
Cypher & $150 \mu \mathrm{m}(0.0055$ inch + polymer) & $7.5 \pm 11.9 \mu \mathrm{m}$ & $11.2 \pm 13.6 \mu \mathrm{m}$ & $26.2 \pm 13.4 \mu \mathrm{m}$ \\
Taxus Express & $148 \mu \mathrm{m}(0.0052$ inch + polymer) & $2.3 \pm 12.6 \mu \mathrm{m}$ & $21.3 \pm 14.9 \mu \mathrm{m}$ & $26.0 \pm 15.1 \mu \mathrm{m}$ \\
\hline
\end{tabular}

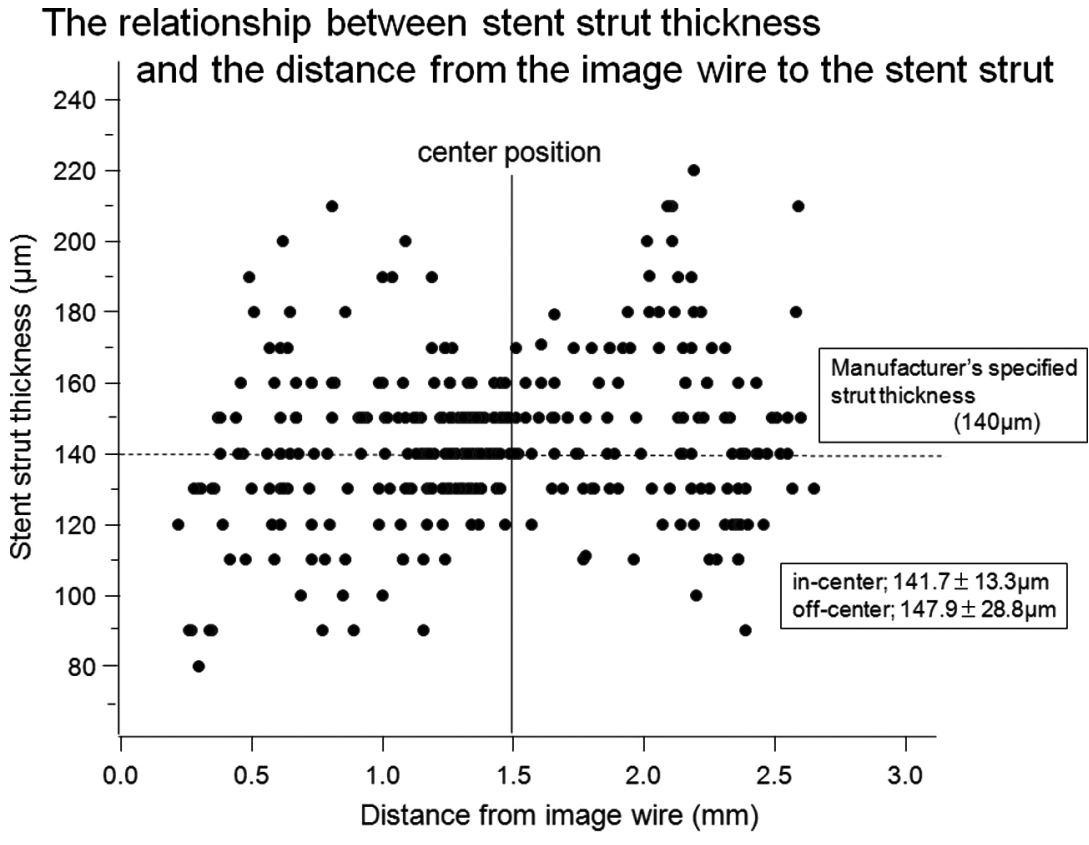

Figure 4. The relationship between stent strut thickness and the distance from the image wire to the stent strut. The distribution of the strut thickness measurements was greater with either an increase or decrease in the distance from the image wire. image wire was low. Furthermore, the motion artifact rate of the $8.2 \mathrm{~F} / \mathrm{s}$ frame-rate images $(15.5 \%)$ was larger than that of the $15.6 \mathrm{~F} / \mathrm{s}$ frame-rate images $(8.1 \%)$.

\section{The Measurements of Stent Strut Thickness}

We analyzed 232 struts of Velocity ${ }^{\mathrm{TM}}$ stents, 166 struts of Express $^{\mathrm{TM}}$ stents, 158 struts of Duraflex ${ }^{\mathrm{TM}}$ stents, 118 struts of Driver ${ }^{\mathrm{TM}}$ stents, 212 struts of TSUNAMITM stents, 149 struts of Cypher ${ }^{\mathrm{TM}}$ stents and 177 struts of Taxus Express ${ }^{\mathrm{TM}}$ stents. In all models, the stents were well apposed (ie, the inner surface of the model was indented by the stent strut was detected). The stent strut thickness measurements with the 3 methods of OCT measurement and the manufacturer's specified strut thickness are shown in Table 3. In both types of stents (BMS and DES), the Dis. A measurements were almost equal to the manufacturer's specification in comparison with those of the Dis. B and Dis. C measurements.

In the Velocity ${ }^{\mathrm{TM}}$ stent, the strut thickness measurement (Dis. A) of the in-center was $141.7 \pm 13.3 \mu \mathrm{m}$. However, the thickness of the off-center was $147.9 \pm 28.8 \mu \mathrm{m}$. The strut of the off-center had a greater thickness $(\mathrm{P}=0.008)$ and a greater distribution than that of the in-center. As for the measurements of stent strut thickness in relation to the distance from the image wire, the distribution of the strut thickness measurements was greater with either an increase or decrease in the distance from the image wire (Figure 4).

To estimate the intra- and inter-observer reproducibility of stent strut thickness measurements obtained by OCT, we drew scatter grams of the Bland Altman plot of the Velocity ${ }^{\mathrm{TM}}$ strut thickness measurements. The estimated limit of agreement for the intra- and inter-observer variability in the measurements of Velocity strut thickness by OCT were also reasonable [Dis. A (mean difference, \%error): intra-observer, $0.8 \pm 9.6 \mu \mathrm{m}, 5.9 \%$ : inter-observer, $1.1 \pm$ $11.4 \mu \mathrm{m}, 8.1 \%$; Dis. B (mean difference, \%error): intraobserver, $1.9 \pm 9.9 \mu \mathrm{m}, 12.1 \%$; inter-observer, $3.1 \pm 12.1 \mu \mathrm{m}$, $19.8 \%$; Dis. C (mean difference, \%error): intra-observer, $1.6 \pm 9.7 \mu \mathrm{m}, 13.1 \%$; inter-observer, $2.9 \pm 11.8 \mu \mathrm{m}, 23.7 \%$ ]. Furthermore, the variability of stent strut thickness was smallest when measured by Dis. A.

\section{Discussion}

The findings of the present study indicated that the crosssectional OCT measurements and the shapes of the visual images were affected by frame acquisition rate and image wire position. The precision of the longitudinal OCT measurements was basically satisfactory, except for that of an angulated lesion. Furthermore, stent strut thickness could be measured accurately with OCT when the distance between the midpoint of the stent strut reflection and the adjacent vessel wall surface was measured for both stent types (BMS and DES).

In the present study, there was an increase in the error and dispersion of the OCT measurements of diameter and area when the OCT image wire was positioned eccentrically 
toward the side of the model wall (off-center), especially when using a lower frame-rate than specified by the manufacturer, in which case the diameter was larger than the actual model value. Further, OCT cross-sectional images were distorted and became elliptical under these conditions (off-center with a low frame-rate). We speculate that 2 main mechanisms are involved in this phenomenon. One is the diagonal cross-sections of the OCT images. Previous studies revealed that IVUS overestimates vessel measurements as a result of non-coaxial IVUS imaging, especially in angulated segments. ${ }^{14,15}$ In the case of IVUS, the impact of catheter angulation on vessel lumen measurements might be small because the size of the IVUS image catheter in relation to the coronary artery lumen is relatively large. ${ }^{16}$ With the OCT image wire, however, non-coaxial imaging might occur more frequently because the image wire catheter is slimmer than the IVUS catheter. The second mechanism might be a deviation of the lateral resolution as the distance from the image wire increases, although the longitudinal axial resolution is unchanged. The OCT light source emits a light beam radially, which tends to increase the lateral value of the region of interest, which is separated from the image wire. Therefore, the OCT image is relatively distorted when the image wire is positioned off-center and the cross-sectional measurements are large.

Furthermore, the motion artifact (so called sew-up) increased at the low frame acquisition rate. Consistent with our data, a previous study demonstrated some motion artifacts at $4 \mathrm{~F} / \mathrm{s}$ and acquisition rates needed to be slightly higher for accurate representation of the luminal diameter. ${ }^{6}$ We speculate that the mechanism underlying these phenomena might be the relatively long time require to collect the OCT images and the rotation irregularity of the OCT image wire. In the present study, some motion artifacts were detected, although we fixed the image wire as much as possible. Nevertheless, the motion artifact might be due to the movement of the image wire induced by the rotating mirror in the catheter. Further, the brightness of the far side phantom surface from the image wire was low. In IVUS, the time-gain compensation is adjusted for the intensity of the image with regard to the distance, ${ }^{17}$ but the OCT system does not have this function. Therefore, there is a visual difference in the intensity of the OCT image.

As for the longitudinal measurements, the OCT measurements of length were identical to the actual values especially in the straight model. In the angulated model, however, the OCT measurements were shorter than the actual values. These phenomena might be due to the short cutting of the lesion. Therefore, OCT measurements of tortuous lesions might underestimate lesion length when OCT is used in vivo.

Infra-red light does not transmit through metal because of light penetration limitation, therefore stent strut thickness must be taken into account in evaluating stent apposition using OCT. Although there are some reports of stent malapposition observed with OCT, ${ }^{9-12}$ the definition of stent malapposition as determined by OCT has not been established. Therefore, we should determine the most accurate measurement point of the stent strut surface with OCT for evaluating stent apposition. The results of the present study indicate that the OCT measurements of stent strut thickness were more accurate when measured from the midpoint of the stent strut reflection than from the inner (Dis. B) or outer (Dis. C) surface stent strut reflection. The light reflection of the stent strut might make the strut appear wider because of diffraction, so that the measurement of strut thickness by OCT might be different from the actual thickness when measured from the inner or outer surface of reflection. Therefore, measurements of Dis. A were closer to the actual stent thickness. Further, stent malapposition could be more accurately evaluated when stent strut thickness was measured using this method. We propose that a criterion of stent malapposition should be that the distance from the stent strut surface to the vessel wall is greater than the OCT axial resolution $(20 \mu \mathrm{m})$ plus the actual thickness of stent strut thickness, which is measured as Dis. A.

The significance of OCT measurements for coronary intervention is not established yet. When IVUS is used for performing PCI, a stent with a larger diameter and smaller length can be used. ${ }^{18,19}$ Therefore, IVUS-guided-PCI can reduce the rates of restenosis after stent implantation. Our data show, however, that OCT could be used to measure almost identical lesion lengths, but not to measure the inner surface of the model because of poor penetration. Yamaguchi et al. also demonstrated that $87.8 \%$ of OCT images of the vessel border at a minimum lumen site were poor as a result of low penetration. ${ }^{20}$ If OCT-guided-PCI is performed, the restenosis rate might be high, especially with bare metal stents because OCT is not suitable for measuring vessel size or selecting a large stent size. Now that drug-eluting stents are available, however, the restenosis rate after stent implantation has been dramatically reduced, even in small vessels and for long lesions, ${ }^{21-23}$ and the major concern of post-DES implantation is now late-stent thrombosis. Recently, late-stent thrombosis from a DES was speculated to be partially because of stent malapposition. ${ }^{24,25}$ Thus, a significant factor of mortality after DES implantation might not be the size of the stent, but rather the apposition of the stent. In our opinion, the advantage of OCT-guided-PCI is the accurate evaluation of stent apposition.

\section{Study Limitations}

This study was an in vitro simple phantom model examination. Therefore, we could not examine all conceivable clinical conditions. We did not evaluate the effect of heart motion on OCT measurements. In IVUS, longitudinal movement of the IVUS transducer within the coronary vessel occurs during the cardiac cycle. ${ }^{26}$ We speculate that the same phenomena would be observed with OCT measurements, and therefore suggest that the pullback speed should be as fast as possible in clinical measurement conditions to reduce artifacts induced by heart motion.

Further, actual vessels are irregular and their tissues are not uniform in comparison with the phantom model's wall, so the evaluation of stent position might be affected by the characteristics of the vessel wall in clinical circumferences. OCT cannot penetrate the stent strut to visualize the tissue underlying the stent strut and infra-red light is generally attenuated by lipid content and red thrombi. ${ }^{27,28}$ Therefore, the position of the stent strut could be misdiagnosed when implanted in lipid-rich or red thorombus-rich plaque.

Furthermore, we generally need to occlude blood flow by occlusion catheter in clinical setting, although several reports showed the effectiveness of non-occlusion OCT image acquisition technique. ${ }^{29,30}$ In the present study, however, the effect of vessel occlusion and saline flashing was not considered. Yamaguchi et al reported the minimum lumen diameter and area by OCT were smaller than IVUS measurements because the decrease in intracoronary pressure 
during OCT imaging resulting from vessel occlusion. ${ }^{20}$

Finally, although we fixed the image wire in place as much as possible, the motion artifact was appeared. Therefore, if we used OCT in vivo, the motion artifact and the error of longitudinal measurements would be larger than the data of the current study.

\section{Conclusion}

In conclusion, we could obtain accurate measurements of lumen diameter and area, and stent strut thickness by OCT when the frame-rate is high and the image wire is positioned at the center. In addition, the longitudinal measurement of OCT is almost identical except for angulated lesion. In DES era, OCT could be a useful tool for PCI procedure when we used it at manufacturer specified frame acquisition rate $(15.6 \mathrm{~F} / \mathrm{s})$. However, we should pay attention that the OCT measurements were affected on position of image wire and vessel morphology.

\section{References}

1. Fitzgerald PJ, St Goar FG, Connolly AJ, Pinto FJ, Billingham ME, Popp RL, et al. Intravascular ultrasound imaging of coronary arteries: Is three layers the norm? Circulation 1992; 86: 154-158.

2. Gorge G, Haude M, Baumgart D, Caspari G, Leischik R, Liu F, et al. Intravascular ultrasound: A guide for management of complication during intervention. Eur Heart J 1995; 16: 86-92.

3. Kawasaki M, Takatsu H, Noda T, Sano K, Ito Y, Hayakawa K, et al. In vivo quantitative tissue characterization of human coronary arterial plaques by use of integrated backscatter intravascular ultrasound and comparison with angioscopic findings. Circulation 2002; 105: $2487-2492$.

4. Von Birgelen C, Kutryk MJB, Gil R, Ozaki Y, Dimario C, Roelandt J, et al. Quantification of the minimum luminal cross-sectional area after coronary stenting by two- and three-dimensional intravascular ultrasound versus edge detection and videodensitometry. Am J Cardiol 1996; 78: 520-525.

5. Huang D, Swanson EA, Lin CP, Schuman JS, Stinson WG, Chang W, et al. Optical coherence tomography. Science 1991; 254: 1178-1181.

6. Fujimoto JG, Boppart SA, Tearney GJ, Bouma BE, Pitris C, Brezinski ME. High resolution in vivo intra-arterial imaging with optical coherence tomography. Heart 1999; 82: 128-133.

7. Kume T, Akasaka T, Kawamoto T, Watanabe N, Toyota E, Neishi Y, et al. Assessment of coronary intima-media thickness by optical coherence tomography. Circ J 2005; 69: 903-907.

8. Kume T, Akasaka T, Kawamoto T, Okura H, Watanabe N, Toyota E, et al. Measurement of the thickness of the fibrous cap by optical coherence tomography. Am Heart J 2006; 152: 755.e1-755.e4.

9. Matsumoto D, Shite J, Shinke T, Otake H, Tanino Y, Ogasawara D, et al. Neointimal coverage of sirolimus-eluting stents at 6-month follow-up: Evaluated by optical coherence tomography. Eur Heart $J$ 2007; 28: 961-967.

10. Sawada T, Shite J, Shinke T, Watanabe S, Otake H, Matsumoto D, et al. Persistent malapposition after implantation of sirolimus-eluting stent into intramural coronary hematoma- optical coherence tomography observations. Circ J 2006; 70: 1515-1519.

11. Katoh H, Shite J, Shinke T, Matsumoto D, Tanino Y, Ogasawara D, et al. Delayed neointimalization on sirolimus-eluting stents: 6-month and 12-month follow up by optical coherence tomography. Circ J 2009; 73: $1033-1037$.

12. Tanigawa J, Barlis P, Di Mario C. Heavily calcified coronary lesions preclude strut apposition despite high pressure balloon dilatation and rotational atherectomy: In-vivo demonstration with optical coherence tomography. Circ J 2008; 72: 157-160.
13. Sawada T, Shite J, Garcia-Garcia HM, Shinke T, Watanabe S, Otake $\mathrm{H}$, et al. Feasibility of combined use of intravascular ultrasound radiofrequency data analysis and optical coherence tomography for detecting thin-cap fibroatheroma. Eur Heart J 2008; 29: 1136-1146.

14. Nishimura RA, Edwards WD, Warnes CA, Reeders GS, Holmes DR $\mathrm{Jr}$, Tajik AJ, et al. Intravascular ultrasound imaging: In vitro validation and pathologic correlation. J Am Coll Cardiol 1990; 16: 145-154.

15. Geselschap JH, Heilbron MJ, Hussain FM, Daskalakis TM, Wilson EP, Kopchok GE, et al. The effect of angulation on intravascular ultrasound imaging observed in vascular phantoms. J Endovasc Surg 1998; 5: 561-574.

16. St Goar FG, Pint FJ, Alderman EL, Fitzgerald PJ, Staudia ML, Popp RL. Intravascular ultrasound imaging of angiographically normal coronary arteries: An in vivo comparison with quantitative angiography. J Am Coll Cardiol 1991; 18: 952-958.

17. Mints GS, Nissen SE, Anderson WD, Bailey SR, Erbel R, Fitzgerald PJ, et al. American College of Cardiology Clinical Expert Consensus Document on Standards for Acquisition, Measurement and Reporting of Intravascular Ultrasound Studies (IVUS): A report of the American College of Cardiology Task Force on Clinical Expert Consensus Documents. J Am Coll Cardiol 2001; 37: 1478-1492.

18. Fitzgerald PJ, Oshima A, Hayase M, Metz JA, Bailey SR, Baim DS, et al. Final results of the Can Routine Ultrasound Influence Stent Expansion (CRUISE) study. Circulation 2000; 102: 523-530.

19. Kasaoka S, Tobis JM, Akiyama T, Reimers B, Di Mario C, Wong $\mathrm{ND}$, et al. Angiographic and intravascular ultrasound predictors of in-stent restenosis. J Am Coll Cardiol 1998; 32: 1630-1635.

20. Yamaguchi T, Terashima M, Akasaka T, Hayashi T, Mizuno K, Muramatsu T, et al. Safety and feasibility of an intravascular optical coherence tomography image wire system in the clinical setting. $A m$ J Cardiol 2008; 101: 562-567.

21. Morice MC, Serruys PW, Sousa JE, Fajadet J, Hayashi EB, Perin M, et al. A randomized comparison of a sirolimus-eluting stent with a standard stent for coronary revascularization: Randomized study with the sirolimus-coated Bx velocity balloon expandable stent in the treatment of patients with de novo native coronary lesions. $N$ Engl $J$ Med 2002; 346: $1773-1780$.

22. Moses JW, Leon MB, Popma JJ, Fitzgerald PJ, Holmes DR, O'Shaughnessy C, et al. Sirolimus-eluting stents versus standard stents in patients with stenosis in a native coronary artery. $N$ Engl $J$ Med 2003; 349: 1315-1323.

23. Stone GW, Ellis SG, Cox DA, Hermiller J, O'Shaughnessy C, Mann JT, et al. TAXUS-IV investigators: A polymer-based, paclitaxel eluting stent in patients with coronary artery disease. $N$ Engl $J$ Med 2004; 350: $221-231$

24. Feres F, Costa JR, Abizaid A. Very late thrombosis after drug-eluting stents. Catheter Cardiovasc Interv 2006; 68: 83-88.

25. Sawada T, Shite J, Shinke T, Tanino Y, Ogasawara D, Kawamori H, et al. Very late thrombosis of sirolimus-eluting stent due to late malapposition-serial observations with optical coherence tomography. J Cardiol 2008; 52: 290-295.

26. Arbab-Zadeh A, Demaria AN, Penny WF, Russo RJ, Kinmura BJ, Bhargava V. Axial movement of the intravascular ultrasound probe during the cardiac cycle: Implications for three-dimensional reconstruction and measurements of coronary dimensions. Am Heart $J$ 1999; 138: $865-872$.

27. Yabushita H, Bouma BE, Houser SL, Aretz HT, Jang IK, Schlendorf $\mathrm{KH}$, et al. Characterization of human atherosclerosis by optical coherence tomography. Circulation 2003; 107: 113-119.

28. Tanimoto T, Imanishi T, Tanaka A, Yamano T, Kitabata H, Takarada $\mathrm{S}$, et al. Various types of plaque disruption in culprit coronary artery visualized by optical coherence tomography in a patient with unstable angina. Circ J 2009; 73: 187-189.

29. Kataiwa H, Tanaka A, Kitabata H, Imanishi T, Akasaka T. Safety and usefulness of non-occlusion image acquisition technique for optical coherence tomography. Circ J 2008; 72: 1536-1537.

30. Prati F, Cera M, Ramazzotti V, Imola F, Giudice R, Propris SD, et al. From bench to bedside: a novel technique of acquiring OCT images. Circ J 2008; 72: 839-843. 